Atualidades de Pesquisa

\title{
CONHECIMENTO E DESEJO NAS FORMULAÇÕES INFANTIS
}

\section{Tese de Doutorado na Faculdade de Educação da Universidade de São Paulo}

\author{
Autora \\ Julia Maria Borges Anacleto \\ Orientador \\ Prof. Dr. Leandro de Lajonquière \\ (Universidade de São Paulo)
}

Banca examinadora

Profa. Dra. Anna Carolina Lo Bianco (Universidade Federal do Rio de Janeiro), Profa. Dra. Luci Banks-Leite (Universidade Estadual de Campinas), Prof. Dr. Cristóvão Giovani Burgarelli (Universidade Federal de Goiás), Prof. Dr. Rinaldo Voltolini (Universidade de São Paulo) 
D. e que modo a psicanálise pode incidir sobre o debate acerca do que impulsiona o pensamento às novidades epistêmicas? De um lado, vemos estudos de psicologia do desenvolvimento que adotam a psicanálise como teoria da afetividade capaz de integrar-se aos pressupostos psicológicos juntamente com a epistemologia genética. A partir dessa montagem teórica, tomam o enunciado da criança como meio de verificação empírica dos aspectos cognitivos e afetivos do desenvolvimento do sujeito psicológico. De outro lado, considera-se o retorno lacaniano à experiência freudiana como fornecendo as bases conceituais para considerar o enunciado da criança como efeito da dialética intersubjetiva da demanda e do desejo. A psicanálise aí se apresenta como recolhendo o que os estudos antes apresentados deixam de lado: a diferença, a discordância ou o desvio que a formulação infantil preserva face à expectativa teórica. Problematizando a naturalização da criança como sujeito em desenvolvimento, surge a brecha para a noção de causa estrutural articulando a diferença e o impulso à emergência de novidades. 